\title{
Low expression IncRNA RPLP0P2 is associated with poor prognosis and decreased cell proliferation and adhesion ability in lung adenocarcinoma
}

\author{
JIE CHEN ${ }^{1 *}$, LIJUAN HU $^{2 *}$, JIAN CHEN $^{2}$, FANG WU $^{3}$, DONGWEI HU ${ }^{2}$, \\ GANG XU ${ }^{2}$, PEIWU ZHU ${ }^{2}$ and YUMIN WANG ${ }^{2}$ \\ Departments of ${ }^{1}$ Intensive Care Unit, ${ }^{2}$ Laboratory Medicine and ${ }^{3}$ Digestive Diseases, \\ The First Affiliated Hospital of Wenzhou Medical University, Wenzhou, Zhejiang 325000, P.R. China
}

Received March 3, 2016; Accepted July 13, 2016

DOI: 10.3892/or.2016.4965

\begin{abstract}
We investigated the clinical roles and biological function of long non-coding (lncRNA) RPLPOP2 in lung adenocarcinoma (LAD). The expression level of RPLP0P2 was estimated by quantitative reverse transcription-polymerase chain reaction (qPCR) in 57 pairs of LAD and NT samples and the relation of RPLP0P2 to clinical data of LAD patients was analyzed. We overexpressed RPLP0P2 based on the human LAD cell line A549 by lentivirus-mediated technology, then oncological behavior change was observed of A549 cells and the change of mRNA level of LRRC10B and RPLP0P2 by qPCR. We found that RPLP0P2 expression was lower while LRRC10B mRNA level was higher in LAD than NT by qPCR. RPLP0P2 expression level was negative correlated to LRRC10B mRNA level (Pearson correlation $=-0.754, \mathrm{P}=0.0021)$. The expression of RPLP0P2 in lymph node metastasis of LAD group was significantly lower than LAD without lymph node metastasis group. Survival analysis showed that survival time of high expression of RPLP0P2 was significantly longer than low RPLP0P2 level in LAD patients. After RPLP0P2 was overexpressed, the proliferation rate, adhesion ability, $\mathrm{S}$ phase and $\mathrm{G} 2 / \mathrm{M}$ phase cells and LRRC10B mRNA significantly reduced, while apoptosis and G0/G1 phase cells obviously increased, but migration ability and invasion did not significantly change. Our study ascertained that low expression of RPLP0P2 in LAD is associated with poor prognosis and decreased prolif-
\end{abstract}

Correspondence to: Dr Yumin Wang, Department of Laboratory Medicine, The First Affiliated Hospital of Wenzhou Medical University, Fuxue Xian 2, Wenzhou, Zhejiang 325000, P.R. China E-mail:wym0577@163.com

*Contributed equally

Key words: lung adenocarcinomas, long non-coding RNA, RPLP0P2, LRRC10B, gene function eration and adhesion ability of tumor cells. LRRC10B may be a downstream gene regulated by RPLP0P2.

\section{Introduction}

Lung cancer is the leading cause of cancer deaths worldwide, and its incidence continues to increase (1). Non-small cell lung cancer (NSCLC) accounts for $\sim 85 \%$ of all lung cancers. Histologically, NSCLC is divided into lung adenocarcinoma (LAD), squamous cell carcinoma (SCC), and large cell carcinoma. Although there has been some progress in chemotherapy, radiation and surgery, lung cancer remains very aggressive and usually rapidly fatal (2). The average 5 -year survival of lung cancer is $<15 \%$ (3-6). In recent years, a growing proportion of LAD is due to socioeconomic development and environmental problems. However, the mechanisms of LAD have not been elucidated.

Studies have shown that IncRNAs are abnormally expressed in tumor cells or tissues and regulate coding gene expression. The altered expression of lncRNAs results in the development, invasion, and metastasis of many cancers with a series of mechanisms $(7,8)$. The regulation of gene expression by lncRNAs at the epigenetic level, transcriptional and post-transcriptional level have been reported (9-11). LncRNAs have been shown to be involved in the development and progression of lung cancer. However, lung cancer-associated lncRNAs are few including HOTAIR, H19, ANRIL, MALAT1 $(12,13)$, SCAL1 (14), AK126698 (15), and GAS6-AS1 (16), so it is very important to identify additional lung cancer-associated lncRNAs and unveil their mechanism of action.

We found that lncRNA RPLP0P2 was downregulated in LAD by high-throughput microarray and real-time quantitative reverse transcription-polymerase chain reaction (qPCR) method in our previous study. Bioinformation analysis showed that LRRC10B might be a target gene regulated by RPLP0P2. However, the clinical roles and biological function of RPLP0P2 are not well understood in LAD. In this study, the expression level of RPLP0P2 was estimated by quantitative PCR in 57 pairs of LAD and NT samples and the relation of RPLPOP2 to clinical data of LAD patients was analyzed. We overexpressed RPLP0P2 based on the human LAD A549 
cell line by lentivirus-mediated technology and observed oncological behavior change of A549 cells.

\section{Materials and methods}

Patient samples. The 57 LAD samples and corresponding NT samples were prospectively collected from patients of the First Affiliated Hospital of Wenzhou Medical University, China, from August 2013 to August 2014. The clinical data of these cases are shown in Table I. The diagnosis of adenocarcinoma was confirmed by histopathology. TNM clinical stage based on the American Joint Committee on Cancer (AJCC) and the Union for International Cancer Control (UICC) in 2002. The LAD and matched NT samples were snap-frozen in liquid nitrogen immediately after resection. We have followed prognosis of 35 LAD patients by telephone or other means, the longest follow-up time was 28 months. According to the expression level of RPLP0P2, the survival data are divided into the high and low expression group. This study was approved by the Institutional Ethics Review Board of the First Affiliated Hospital of Wenzhou Medical University, and all patients provided written informed consent for this study.

Quantitative PCR. Total RNA was extracted from frozen LAD tissues by using TRIzol reagent (Invitrogen). According to the manufacturer's instructions, total RNA was reverse-transcribed into cDNA using an RT Reagent kit (Takara, Shanghai, China). RPLPOP2 and GAPDH mRNA expression in LAD tissues were measured by quantitative PCR by using SYBR Premix Ex Taq in ABI 7000 instrument. RPLP0P2 sense, 5'-AAAAACGATCAACGAACCTT-3' and antisense, 5'-AAT CGTCTCTGCTTTTCTTG-3'; GAPDH sense, 5'-TGACTT CAACAGCGACACCCA-3' and antisense, 5'-CACCCTGTT GCTGTAGCCAAA-3'; LRRC10B sense, 5'-AAGCCACCG TGCCTCCA-3' and antisense, 5'-TCCCTCGTCCCGTTA TTGC-3'. Total RNA (2 mg) was transcribed to cDNA. PCR was performed in a total reaction volume of $20 \mu \mathrm{l}$, including $10 \mu \mathrm{l}$ of SYBR Premix Ex Taq (2X), $2 \mu 1$ of cDNA template, $1 \mu \mathrm{l}$ of PCR forward primer (10 mM), $1 \mu 1$ of PCR reverse primer $(10 \mathrm{mM})$, and $6 \mu \mathrm{l}$ of double-distilled water. The quantitative real-time PCR reaction included an initial denaturation step of $10 \mathrm{~min}$ at $95^{\circ} \mathrm{C} ; 40$ cycles of $5 \mathrm{sec}$ at $95^{\circ} \mathrm{C}, 30 \mathrm{sec}$ at $60^{\circ} \mathrm{C}$; and a final extension step of $5 \mathrm{~min}$ at $72^{\circ} \mathrm{C}$. All experiments were performed in triplicate, and all samples were normalized to GAPDH. The median in each triplicate was used to calculate relative lncRNA concentrations $(\Delta \mathrm{Ct}=\mathrm{Ct}$ median lncRNA - Ct median GAPDH), and $2^{-\Delta \Delta \mathrm{Ct}}$ in expression was calculated (17).

Cell culture. Five human LAD cell lines (SPCA-1, NCI-H1299, A549, NCI-H441, LTEP-a2) were all purchased from the Cell Bank of the Chinese Academy of Sciences and were cultured with complete medium (containing 10\% fetal serum and $90 \%$ RPMI-1640) set at $37^{\circ} \mathrm{C}, 5 \% \mathrm{CO}_{2}$ and complete medium was changed at least once every two days.

Lentivirus-mediated overexpression vector transfection. A549 cells were transfected overexpression vector targeting RPLP0P2 as well as a negative control (GeneChem, Shanghai, China). Transfection was accomplished by seeding $2 \times 10^{5}$ cells into a 6-well plate, and after $24 \mathrm{~h}$, the medium was aspirated and incubated with transfection complex according to the manufacturer's instructions and MOI values $(\mathrm{MOI}=20)$. The A549 cells were infected by lentivirus for $72 \mathrm{~h}$ and the overexpression efficiency was detected by qPCR.

Cell migration and invasion assays. Migration and invasion assay was performed with $8.0-\mu \mathrm{m}$ pore inserts (Millipore, USA) in a 24 -well plate. For migration assay, $2 \times 10^{4}$ cells were seeded into the upper compartment of the Transwell inserts. The invasion assay was performed with Matrigel-coated filters (Sigma Corp., USA). Cells were allowed to incubate for 24 and $48 \mathrm{~h}$, respectively. Migrated and invaded were fixed by methanol and stained by $0.1 \%(\mathrm{w} / \mathrm{v})$ crystal violet, then bleached with $33 \%$ acetic acid and absorbance value measured at $570 \mathrm{~nm}$ on a microplate reader. Each experiment was performed in triplicate.

Cell viability assay. Cell viability was evaluated by Cell Counting kit-8 (CCK-8; Corning, Inc., USA) abiding by the manufacturer's instructions. Briefly, 3,000 cells were resuspended and seeded into a 96-well plate supplemented in the presence of $10 \%$ FBS and cultured for a week. The next day, the RPLP0P2 overexpression cells were incubated with CCK-8 for $1 \mathrm{~h}$ and the absorbance was measured at $450 \mathrm{~nm}$ using a multifunctional microplate reader (Tecan) at day 1, 3, 5 and 7 . This experiment was done in quadruplicate cells.

Cell cycle assay. The cells were harvested by centrifugation and fixed by $70 \%$ ethanol at $4{ }^{\circ} \mathrm{C}$ overnight. The cells were resuspended with $400 \mu \mathrm{l}$ PBS (containing $2 \mathrm{mg} / \mathrm{ml}$ RNA enzymes) and incubated at $37^{\circ} \mathrm{C}$ for $30 \mathrm{~min}$, then added $400 \mu \mathrm{l}$ propidium iodide $(0.1 \mathrm{mg} / \mathrm{ml})$ for $10 \mathrm{~min}$ and detected DNA content by a flow cytometry analyzer (Cytomics FC 500; Beckman Coulter). The results were analyzed using MultiCycle software.

Adhesion assay. The 96-well plates were processed with $50 \mu \mathrm{l}$ FN $(50 \mu \mathrm{g} / \mathrm{ml})$, and no processed wells were the CON group. These wells were added into $2 \times 10^{4}$ cells/well and stained by $0.1 \%(\mathrm{w} / \mathrm{v})$ crystal violet, then dissolved with $2 \%$ SDS and detected at OD550 $\mathrm{nm}$. This experiment was done in quadruplicate cells.

Statistical methods. Differences in variables among groups were tested using the one-way ANOVA for the normal distribution or Kruskal-Wallis test for the non-normal distribution. A comparison between the two groups was performed by least significant difference (LSD) test or Student's t-test or Mann-Whitney U test. Survival analysis was performed using Chi-square test. $\mathrm{P}<0.05$ was considered to be statistically significant.

\section{Results}

The expression level of RPLPOP2 in lung cancer and adjacent tissues and analysis of its relationship with clinical data. According to Table I, RPLPOP2 expression level of LAD is $0.287(0.131-2.96)$ and significantly lower than its adjacent cancer tissues (Mann-Whitney $\mathrm{U}=2.120, \mathrm{P}=0.0029$ ). We showed that the RPLPOP2 level of LAD with lymph node 
Table I. The clinical features of 57 LAD patients and the relative expression levels of RPLP0P2.

\begin{tabular}{|c|c|c|c|c|}
\hline Term & Case (n) & $\begin{array}{l}\text { RPLPOP } 2 \text { relative } \\
\text { expression level }\end{array}$ & $\begin{array}{c}\text { Kruskal-Wallis or } \\
\text { Mann-Whitney U test }\end{array}$ & P-value \\
\hline Gender & & & 287.00 & 0.423 \\
\hline Male & 28 & $0.792(0.160-1.130)$ & & \\
\hline Female & 29 & $1.064(0.028-1.675)$ & & \\
\hline TNM stage & & & 7.124 & 0.154 \\
\hline Ia & 12 & $0.757(0.098-1.293)$ & & \\
\hline $\mathrm{Ib}$ & 28 & $0.604(0.041-1.487)$ & & \\
\hline IIa & 7 & $0.458(0.097-1.359)$ & & \\
\hline IIb & 2 & $0.893(0.908-1.193)$ & & \\
\hline IIIa & 8 & $1.200(0.016-1.772)$ & & \\
\hline Histological degree & & & 3.235 & 0.676 \\
\hline Poor & 11 & $1.000(0.160-1.412)$ & & \\
\hline Poor-moderate & 7 & $1.014(0.097-1.134)$ & & \\
\hline Moderate & 17 & $0.463(0.064-1.773)$ & & \\
\hline Moderate-high & 9 & $0.732(0.318-1.004)$ & & \\
\hline High & 13 & $1.117(0.092-1.273)$ & & \\
\hline Lymph node metastasis & & & 9.102 & 0.011 \\
\hline Yes & 14 & $0.130(0.081-0.387)$ & & \\
\hline No & 43 & $1.659(0.362-2.96)$ & & \\
\hline Smoking & & & 321.00 & 0.165 \\
\hline Yes & 20 & $0.732(0.154-1.266)$ & & \\
\hline No & 37 & $0.917(0.104-1.004)$ & & \\
\hline
\end{tabular}

LAD, lung adenocarcinoma.

metastasis was significantly lower than that of LAD without lymph node metastasis group (Mann-Whitney $U=9.102$, $\mathrm{P}=0.011)$. RPLP0P2 expression levels among different clinical stages were not different (Kruskal-Wallis test $=7.124$, $\mathrm{P}=0.154)$. The expression of RPLP0P2 was not relative to the histology differentiation (Kruskal-Wallis test=3.235, $\mathrm{P}=0.676$ ), smoking (Mann-Whitney $\mathrm{U}=321.00, \mathrm{P}=0.165$ ), or gender (Mann-Whitney $\mathrm{U}=287.00, \mathrm{P}=0.423$ ). LRRC10B mRNA expression level of LAD was significantly higher than its adjacent cancer tissues (Mann-Whitney $U=1.530, \mathbf{P}=\mathbf{0 . 0 0 0}$ ). Pearson correlation analysis showed that RPLP0P2 expression levels were negatively correlated to LRRC10B mRNA levels (Pearson correlation $=-0.754, \mathrm{P}=0.0021)($ Fig. 1).

RPLPOP2 expression in lung cancer prognosis. The overall survival time of LAD low expression RPLP0P2 group (median 10 months) was significantly lower than that of the high expression (median 26 months) $\left(\chi^{2}=18.81, \mathrm{P}<0.0001\right)$ (Fig. 2).

The expression level of RPLPOP2 fom five LAD cells. Compared to normal human bronchial epithelial BEAS-2B cell line, we detected the expression levels of RPLPOP2 from five LAD cell lines (including A549, NCI-H441, NCI-H1299, SPCA-1, LETP-a2) by qPCR. It was shown that the expression levels of RPLP0P2 from LETP-a2, SPCA-1, NCI-H441 cells were highly expressed wherein LETP-a2 was the highest and that of SPCA-1, NCI-H441 were moderately expressed,

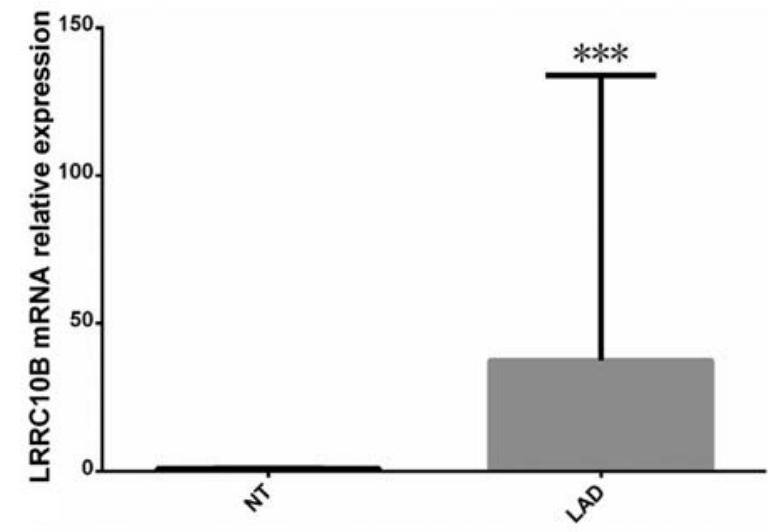

Figure 1. The relative expression levels of RPLP0P2 in lung adenocarcinoma (LAD) and NT tissues. LRRC10B mRNA expression level of LAD was significantly higher than its adjacent cancer tissues $\left({ }^{* * * *} \mathrm{P}<0.001\right)$.

while that of A549 and NCI-H1299 cells the lowest (Fig. 3). Therefore, A549 cells were lentivirus-mediated transfection RPLP0P2 overexpression cells.

The expression levels of RPLPOP2 and LRRC1OB in three A549 cell groups. The expression levels of RPLP0P2 in three A549 cell groups were different $(\mathrm{F}=117.00, \mathrm{P}<0.0001)$ and that of overexpression A549 cells was higher than that of the NC group $(t=10.34, P=0.0005)$, control group $(t=10.81$, 


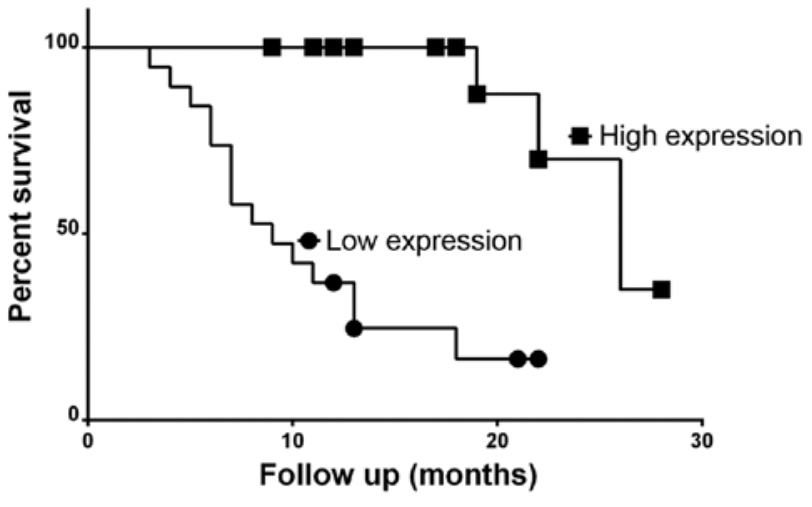

Figure 2. The relation of RPLP0P2 expression to prognosis in lung adenocarcinoma (LAD) patients. The overall survival time of LAD low expression RPLPOP2 group was significantly lower than that of the high expression.

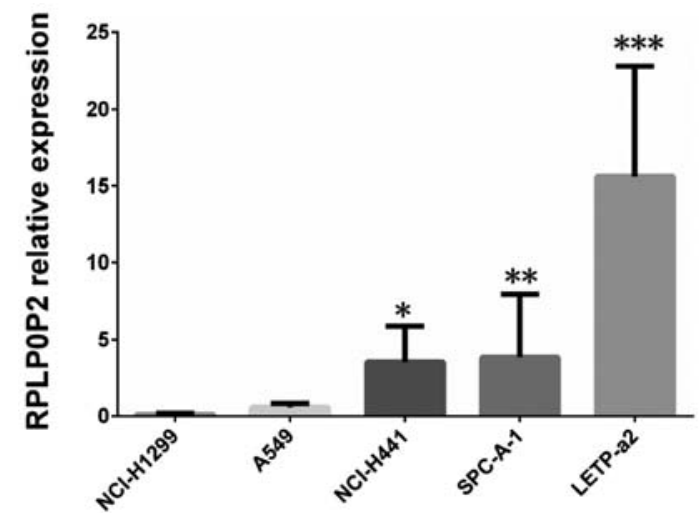

Figure 3. The expression levels of RPLPOP2 in five lung adenocarcinoma (LAD) cell lines. ${ }^{*} \mathrm{P}<0.05,{ }^{* * *} \mathrm{P}<0.01,{ }^{* * *} \mathrm{P}<0.001$, when compared to BEAS-2B.

$\mathrm{P}=0.0004$ ) (Fig. 4). The LRRC10B mRNA expression levels of three A549 cell groups were different $(\mathrm{F}=29.11, \mathrm{P}=0.0008)$ and that of RPLP0P2 overexpression A549 cells was lower than that of $\mathrm{NC}$ group $(\mathrm{t}=5.909, \mathrm{P}=0.0042)$, or control group $(\mathrm{t}=6.056, \mathrm{P}=0.0037)$. While RPLP0P2 expression levels were not changed significantly after LRRC10B siRNA ( $\mathrm{F}=0.4489$, $\mathrm{P}=0.6582$ ). These experiments hinted that LRRC10B may be a downstream gene regulated by RPLPOP 2 .

RPLPOP2 is not related to cell migration and invasion. The OD570 value of three A549 cell groups was not different $(\mathrm{F}=1.262, \mathrm{P}=0.3488)$, the OD570 value of RPLP0P2 overexpression A549 cells was similar to that of $\mathrm{NC}$ group ( $\mathrm{t}=1.715$, $\mathrm{P}=0.153)$, and control group ( $\mathrm{t}=0.7292, \mathrm{P}=0.506)$ (Fig. 5). Thus, the cell migration ability of A549 cells did not change after RPLP0P2 was overexpressed. According to Fig. 6, the OD570 value of the three A549 cell groups was not different $(\mathrm{F}=0.9129, \mathrm{P}=0.4507)$ the OD570 value of RPLP0P2 overexpression A549 cells was similar to that of $\mathrm{NC}$ group $(\mathrm{t}=0.9879$, $\mathrm{P}=0.3791)$, and control group $(\mathrm{t}=1.196, \mathrm{P}=0.2979)$.

RPLPOP2 expression level is associated with cell proliferation and adhesion. Fig. 7 shows the OD450 nm of different A549 groups gradually increased with the change of time. Compared with day 1 , the OD450 $\mathrm{nm}$ of day $3(\mathrm{P}<0.05, \mathrm{P}<0.05, \mathrm{P}<0.05)$,

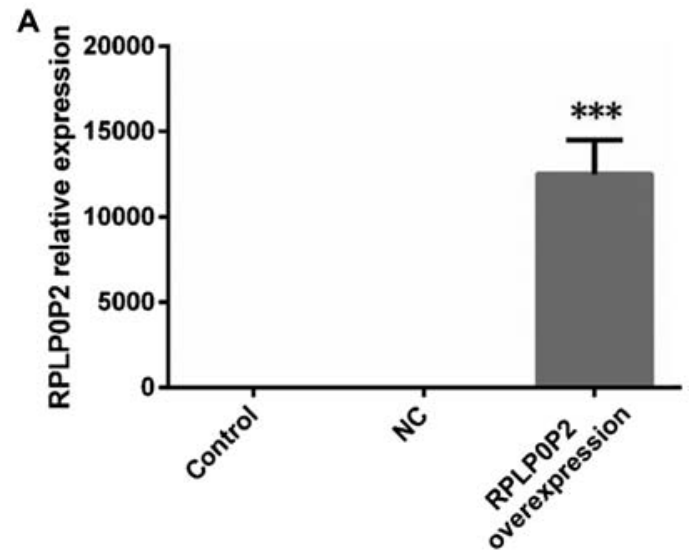

B
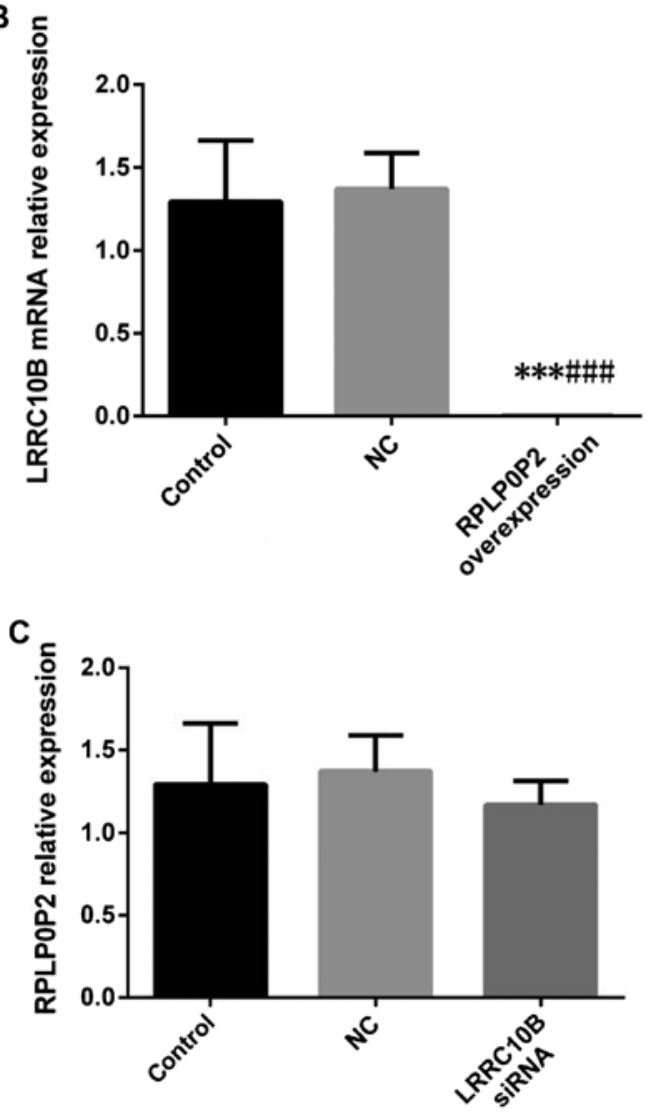

Figure 4. The RPLP0P2 and LRRC10B mRNA expression level of three A549 cell groups. (A) RPLP0P2 and (B) LRRC10B mRNA expression levels of three A549 cell groups after RPLP0P2 siRNA, (C) RPLP0P2 expression level after LRRC10B siRNA. ${ }^{* * *} \mathrm{P}<0.001,{ }^{\# \# \#} \mathrm{P}<0.001$.

day $5(\mathrm{P}<0.001, \mathrm{P}<0.001, \mathrm{P}<0.01)$, day $7(\mathrm{P}<0.001, \mathrm{P}<0.001$, $\mathrm{P}<0.001)$ were significantly increased. Compared with appropriate days of control and NC group, the OD450 nm of 1 and 3 days in RPLPOP2 overexpression group had no statistically significant difference $(\mathrm{P}>0.05)$, while that of the 5 days $(\mathrm{P}<0.05)$ and the 7 days $(\mathrm{P}<0.01)$ significantly reduced, it indicates that cell proliferation ability of A549 was significantly reduced after RPLPOP2 overexpression. Fig. 8 shows that after RPLP0P2 was overexpressed, $\mathrm{S}$ phase $(\mathrm{P}=0.0002$ and $\mathrm{P}=0.0001)$ and $\mathrm{G} 2 / \mathrm{M}$ phase cells $(\mathrm{P}=0.0004$ and $\mathrm{P}=0.0006)$ of A549 cells significantly reduced, while apoptosis and G0/G1 phase cells $(\mathrm{P}=0.0003$ and $\mathrm{P}=0.0007)$ obviously increased compared to control and $\mathrm{NC}$ groups. The cell cycle results 
A

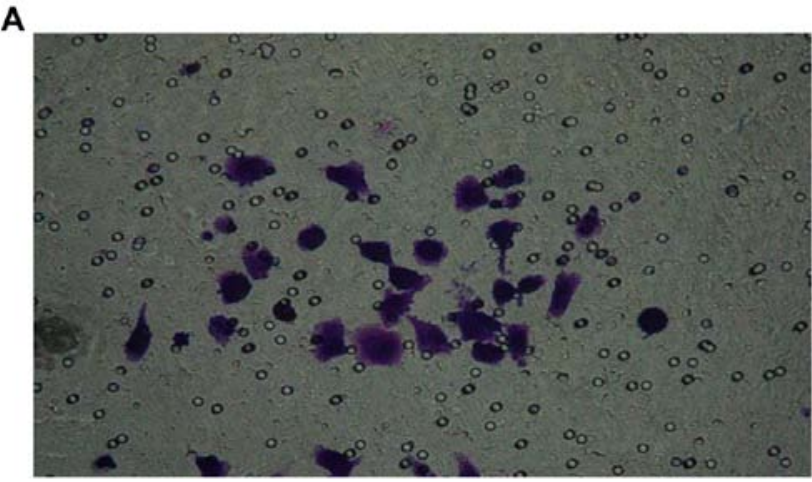

C

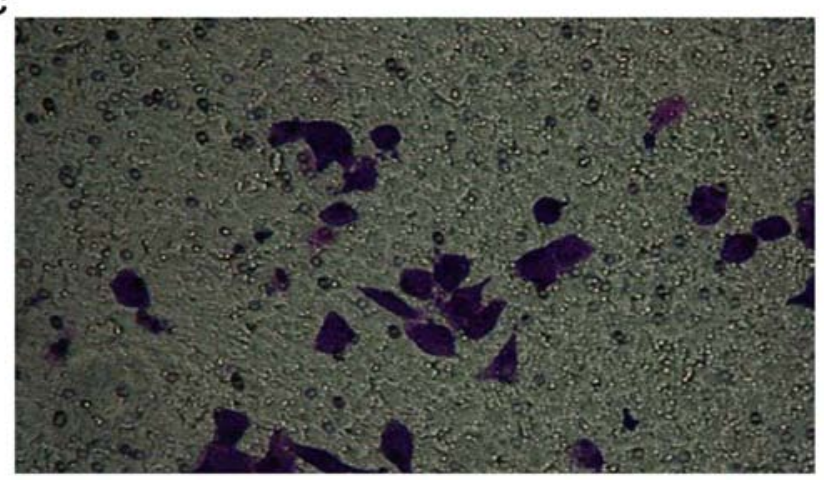

B
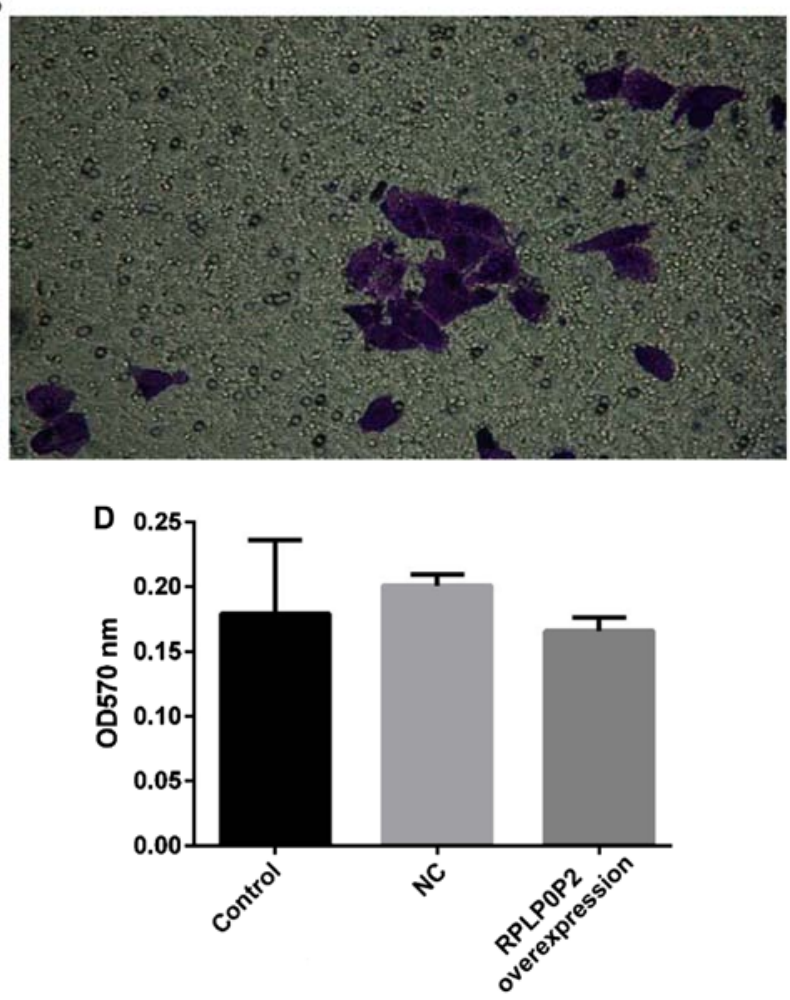

Figure 5. The results of cell migration assay from A549 after RPLP0P2 overexpression. (A) Control, (B) NC, (C) RPLP0P2 overexpression, (D) OD570 nm of three groups. No statistically significant differences were found in the groups.

A

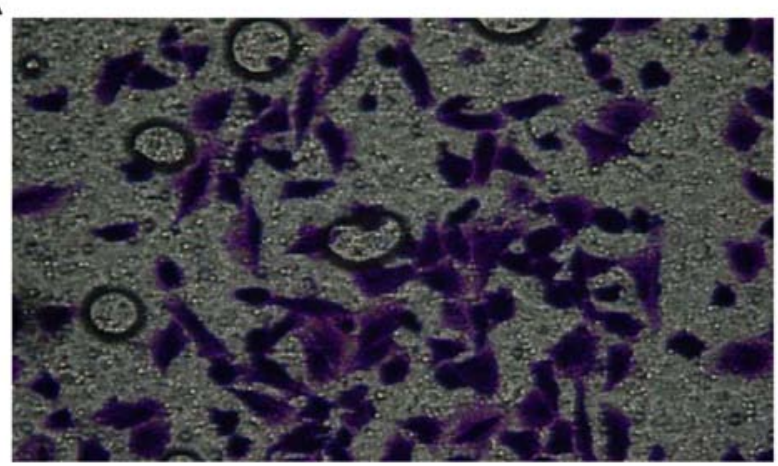

C

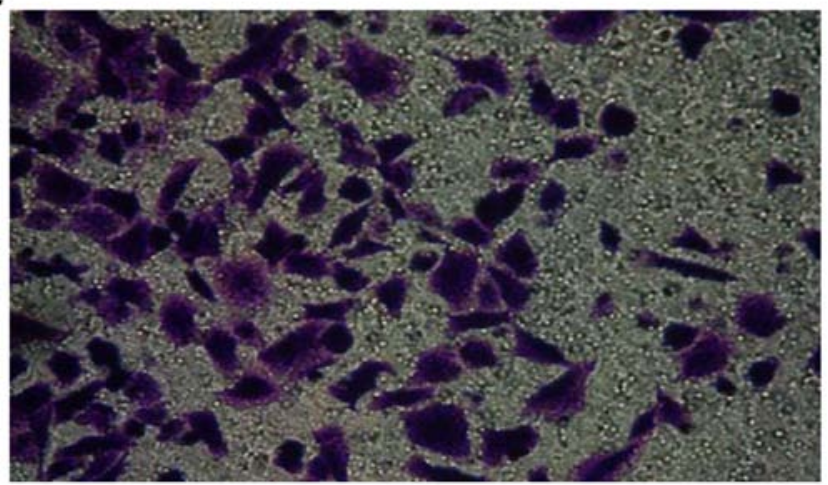

B
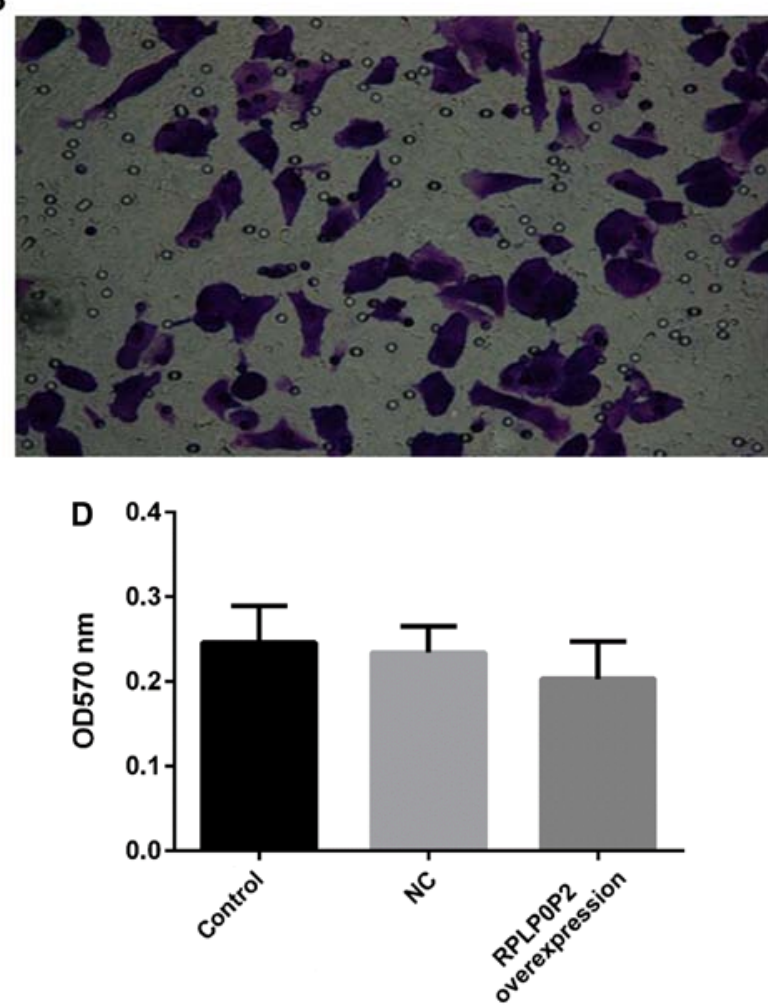

Figure 6. The results of cell invasion assay from A549 after RPLP0P2 overexpression. (A) Control, (B) NC, (C) RPLP0P2 overexpression, (D) OD570 nm of three groups. No statistically significant differences were found in different groups.

further confirmed that the RPLPOP2 expression level was associated with the ability of cell proliferation. The OD550 of control group $(\mathrm{P}<0.05), \mathrm{NC}$ group $(\mathrm{P}<0.05)$ were higher than RPLP0P2 overexpression group among CON group in Fig. 9. 

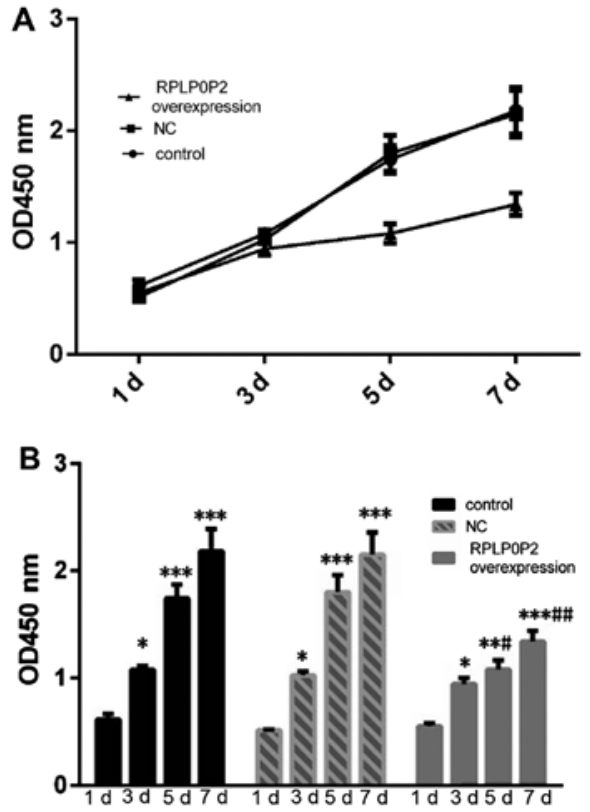

Figure 7. The cell proliferation results of different A549 groups. (A) The different OD values on days 1,3,5 and 7. (B) The OD450 nm line boxplots of different A549 groups at four time points. It shows that the OD450 nm of different A549 groups gradually increased over time. Compared with day 1, the OD450 nm of days 3, 5 and 7 were significantly increased. Compared with appropriate days of control and $\mathrm{NC}$ group, the OD450 $\mathrm{nm}$ of days 1 and 3 in the RPLPOP2 overexpression group had no statistically significant difference, while that of days 5 and 7 was significantly reduced. ${ }^{*} \mathrm{P}<0.05$, ${ }^{* *} \mathrm{P}<0.01,{ }^{* * * *} \mathrm{P}<0.001,{ }^{\#} \mathrm{P}<0.05,{ }^{\# \#} \mathrm{P}<0.01$

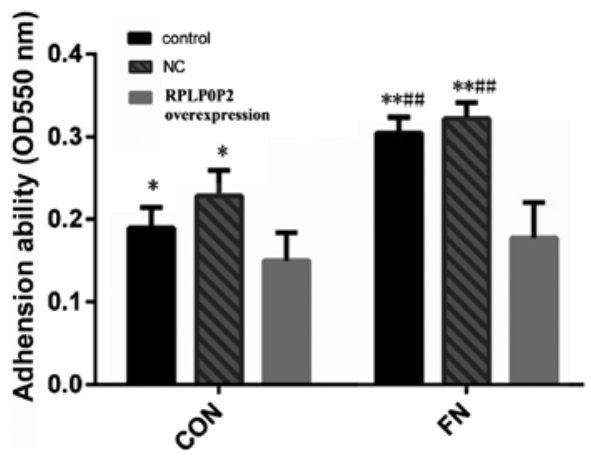

Figure 8. The cell proliferation experiment of different A549 groups. ${ }^{*} \mathrm{P}<0.05$, ${ }^{* * *} \mathrm{P}<0.01,{ }^{\# \#} \mathrm{P}<0.01$

Compared to CON group, the OD550 of control group, NC group from $\mathrm{FN}$ processing significantly increased while that of RPLP0P2 overexpression group was not different. Therefore, it was shown that RPLP0P2 lowered the adhesion capacity of A549 cells after overexpression.

\section{Discussion}

LncRNAs play an important role in many biological processes, including $\mathrm{X}$ chromosome inactivation, gene imprinting $(18,19)$ and also control gene expression and accelerate the development and progression in cancers $(8,20)$. Promoters bind to many transcription factors with mechanisms such as chromosomal rearrangements and transfer elements (21). An important function of lncRNAs can change the expression of
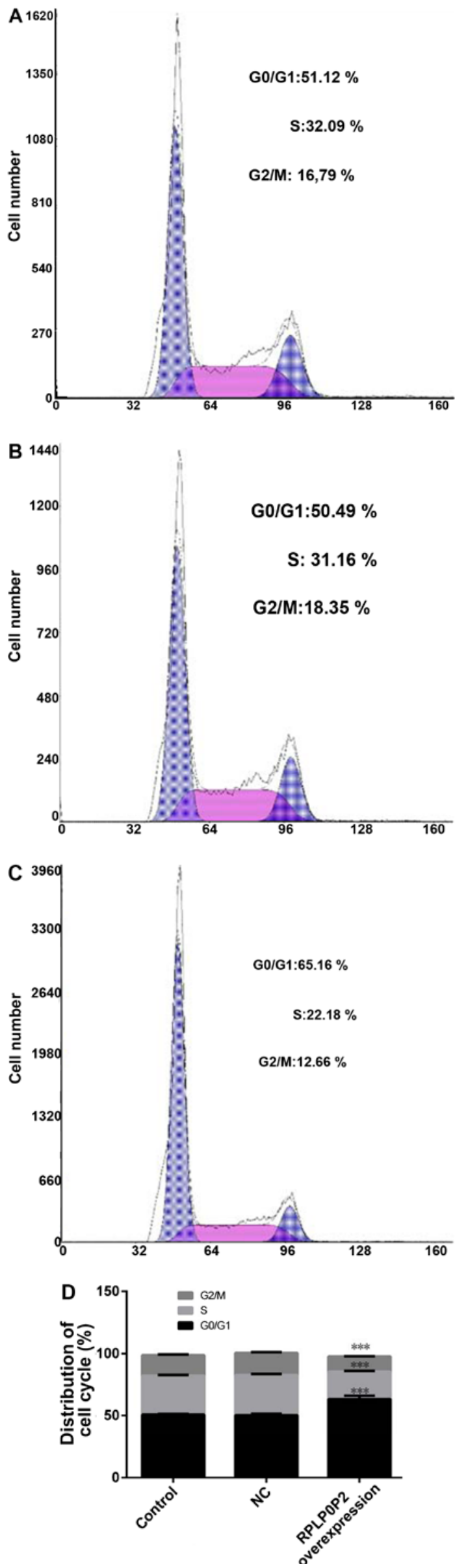

Figure 9. The cell cycle results of three different A549 groups. (A) Control, (B) NC, (C) RPLP0P2 overexpression, (D) distribution of cell cycle. ${ }^{* * *} \mathrm{P}<0.001$. 
nearby encoding genes by affecting the process of transcription (22) or directly playing an enhancer-like role $(23,24)$. Our bioinformation analysis showed that LRRC10B might be a target gene regulated by RPLPOP 2 .

In this study, we uncovered the potential role of RPLP0P2 in the pathogenesis of LAD. We found that RPLP0P2 was lower expressed in LAD by qPCR. The expression of RPLP0P2 in lymph node metastasis of LAD group was significantly lower than LAD without lymph node metastasis group, while it was no relative to TNM stage, degree of tissue differentiation, gender, age, or smoking. Survival time of high expression RPLP0P2 was significantly longer than low RPLPOP2 level in LAD patients, while LRRC10B mRNA level was higher in LAD than NT by qPC. RPLP0P2 expression level negatively correlated to LRRC10B mRNA level. These results hinted that RPLP0P2 is a tumor suppressor and abnormally expressed in LAD.

Compared to normal human bronchial epithelial BEAS-2B cell line, we detected the expression levels of RPLPOP2 from five LAD cell lines. It was shown that the expression levels of RPLP0P2 were highly expressed in LETP-a2, SPCA-1 and NCI-H441, while in A549 and NCI-H1299 cells lowly expressed. In order to further study the mechanism of RPLP0P2 we established RPLP0P2 overexpression of A549 cell line by lentivirus-mediated technology. After RPLP0P2 was overexpressed, the proliferation rate, adhesion ability, $\mathrm{S}$ and G2/M phase cells and LRRC10B mRNA significantly reduced, while apoptosis and G0/G1 phase cells obviously increased, but migration ability and invasion did not significantly change.

To summarize, our study ascertained that the expression of RPLP0P2 is downregulated in LAD and is associated with poor prognosis and decreased proliferation and adhesion ability of tumor cells. LRRC10B may be a downstream gene regulated by RPLP0P2.

\section{Acknowledgements}

This study was financially supported by the National Natural Science Foundation of China (8140736), the Zhejiang Provincial Health Department (2014KYA133), and the Zhejiang Provincial Natural Science Foundation (LQ16H160020).

\section{References}

1. Jemal A, Murray T, Ward E, Samuels A, Tiwari RC, Ghafoor A Feuer EJ and Thun MJ: Cancer statistics, 2005. CA Cancer J Clin 55: 10-30, 2005.

2. Gridelli C, Rossi A and Maione P: Treatment of non-small-cell lung cancer: State of the art and development of new biologic agents. Oncogene 22: 6629-6638, 2003.

3. Stewart DJ: Tumor and host factors that may limit efficacy of chemotherapy in non-small cell and small cell lung cancer. Crit Rev Oncol Hematol 75: 173-234, 2010.

4. Chen CH, Lai JM, Chou TY, Chen CY, Su LJ, Lee YC, Cheng TS, Hong YR, Chou CK, Whang-Peng J, et al: VEGFA upregulates FLJ10540 and modulates migration and invasion of lung cancer via PI3K/AKT pathway. PLoS One 4: e5052, 2009.
5. Ogawa E, Takenaka K, Katakura H, Adachi M, Otake Y, Toda Y, Kotani H, Manabe T, Wada H and Tanaka F: Perimembrane Aurora-A expression is a significant prognostic factor in correlation with proliferative activity in non-small-cell lung cancer (NSCLC). Ann Surg Oncol 15: 547-554, 2008.

6. Rachet B, Woods LM, Mitry E, Riga M, Cooper N, Quinn MJ, Steward J, Brenner H, Estève J, Sullivan R, et al: Cancer survival in England and Wales at the end of the 20th century. Br J Cancer 99 (Suppl 1): S2-S10, 2008.

7. Fu X, Ravindranath L, Tran N, Petrovics G and Srivastava S: Regulation of apoptosis by a prostate-specific and prostate cancer-associated noncoding gene, PCGEM1. DNA Cell Biol 25: 135-141, 2006.

8. Gupta RA, Shah N, Wang KC, Kim J, Horlings HM, Wong DJ, Tsai MC, Hung T, Argani P, Rinn JL, et al: Long non-coding RNA HOTAIR reprograms chromatin state to promote cancer metastasis. Nature 464: 1071-1076, 2010.

9. Zhang H, Chen Z, Wang X, Huang Z, He Z and Chen Y: Long non-coding RNA: A new player in cancer. J Hematol Oncol 6: 37, 2013.

10. Hauptman $\mathrm{N}$ and Glavač D: Long non-coding RNA in cancer. Int J Mol Sci 14: 4655-4669, 2013.

11. Chen G, Wang Z, Wang D, Qiu C, Liu M, Chen X, Zhang Q, Yan $G$ and Cui Q: LncRNADisease: A database for long non-coding RNA-associated diseases. Nucleic Acids Res 41 (D1): D983-D986, 2013.

12. Gibb EA, Brown CJ and Lam WL: The functional role of long non-coding RNA in human carcinomas. Mol Cancer 10: 38, 2011.

13. Ji P, Diederichs S, Wang W, Böing S, Metzger R, Schneider PM, Tidow N, Brandt B, Buerger H, Bulk E, et al: MALAT-1, a novel noncoding RNA, and thymosin beta4 predict metastasis and survival in early-stage non-small cell lung cancer. Oncogene 22: 8031-8041, 2003

14. Thai P, Statt S, Chen CH, Liang E, Campbell C and Wu R: Characterization of a novel long noncoding RNA, SCAL1, induced by cigarette smoke and elevated in lung cancer cell lines. Am J Respir Cell Mol Biol 49: 204-211, 2013.

15. Yang Y, Li H, Hou S, Hu B, Liu J and Wang J: The noncoding RNA expression profile and the effect of lncRNA AK126698 on cisplatin resistance in non-small-cell lung cancer cell. PLoS One 8: e65309, 2013.

16. Han L, Kong R, Yin DD, Zhang EB, Xu TP, De W and Shu YQ: Low expression of long noncoding RNA GAS6-AS1 predicts a poor prognosis in patients with NSCLC. Med Oncol 30: 694, 2013.

17. Ren S, Peng Z, Mao JH, Yu Y, Yin C, Gao X, Cui Z, Zhang J, Yi K, $\mathrm{Xu}$ W, et al: RNA-seq analysis of prostate cancer in the Chinese population identifies recurrent gene fusions, cancer-associated long noncoding RNAs and aberrant alternative splicings. Cell Res 22: 806-821, 2012.

18. Drobnik W, Liebisch G, Biederer C, Tr mbach B, Rogler G, Müller P and Schmitz G: Growth and cell cycle abnormalities of fibroblasts from Tangier disease patients. Arterioscler Thromb Vasc Biol 19: 28-38, 1999

19. Wang KC and Chang HY: Molecular mechanisms of long noncoding RNAs. Mol Cell 43: 904-914, 2011.

20. Khachane AN and Harrison PM: Mining mammalian transcript data for functional long non-coding RNÂs. PLoS One 5: e10316, 2010.

21. Loh YH, Wu Q, Chew JL, Vega VB, Zhang W, Chen X, George J, Leong B, Liu J, et al: The Oct4 and Nanog transcription network regulates pluripotency in mouse embryonic stem cells. Nat Genet 38: 431-440, 2006

22. Mattick JS and Gagen MJ: The evolution of controlled multitasked gene networks: The role of introns and other noncoding RNAs in the development of complex organisms. Mol Biol Evol 18: 1611-1630, 2001.

23. Mattick JS: Lincing Long noncoding RNAs and enhancer function. Dev Cell 19: 485-486, 2010.

24. Ørom UA, Derrien T, Beringer M, Gumireddy K, Gardini A, Bussotti G, Lai F, Zytnicki M, Notredame C, Huang Q, et al: Long noncoding RNAs with enhancer-like function in human cells. Cell 143: 46-58, 2010 